\title{
Holistic approach for cultural infrastructure with reference to future smart cities
}

\author{
Chaitanya Gokhale \\ ${ }^{1}$ MIT ADT University, Loni Kalbhor, Solapur Highway, Pune 412201, India.
}

\begin{abstract}
To take the initiative of smart cities to new heights is a responsibility of every citizen. Bona fide progress will be seen when people's approach towards their city will change through awareness and education about the prevalent systems. This paper focuses on improving the cultural aspects of a smart city, especially visually, and on improving governance with reference to the 21 st century. A majority of the information deals with the must-haves of smart city, later moving on to more specific problems. In the following paper, evaluation, analysis, ideas, innovative solutions along with comparisons and examples from life have been suggested with a view of enhancing the pre-existent, and further developing the cultural infrastructure of a smart city. This is proposed in a way that will help old traditions and historical heritage keep pace with modernism and other urban developments in the age of internet without changing their essence. This, in turn, will lead to touristic developments. Attention has also been paid to heritage restoration and its methods. Special focus has been given to the aesthetics of proposed, self-designed signage systems of the city. It is hoped that the insights presented herewith encourage greater enthusiasm towards art and encourage appreciation towards the culture and heritage of a smart city. This will add value to the quality of life of its citizens. Keywords: Smart City, Culture, Heritage, Aesthetics, Innovation, Governance
\end{abstract}

\section{Introduction}

Let's begin with the most important question. What really makes a city "smart"? [1], The basic infrastructure needed for any city to make progress by using "smart solutions" is undoubtedly a major part of the answer. Some important areas where these smart solutions apply include the following but are not limited to:

- Clean, sustainable environment

- Assured electrical supply and safe water supply with $100 \%$ treatment of waste water

- $\quad$ Sanitation and solid waste management

- Efficient urban mobility and public transport

- $\quad$ Robust IT connectivity

- E-governance and citizen participation through public information and grievance redressal

- Renewable, efficient sources of energy and green building

- Safety and security of citizens

- Effective Visual Communication

- Aesthetic Pleasure

It is necessary to understand that the focus of such technological and infrastructural advancements is to ease human load. Not necessarily making the pace of life faster, but allowing citizens a peaceful space where they can have a rather decent quality of life, with the freedom to live their way, responsibly.

\footnotetext{
${ }^{*}$ Corresponding author: chaigo@gmail.com
}

The art and culture of any city play a vital role in the quality of life of its people. [2,3], They have immediate as well as indirect effects on daily life apart from long-term effects. This paper talks about the different ways in which we can enhance the same, ranging from details like language to broader topics like city attractions. Of course, it is not an individual effort alone and a lot of government aid will be required in achieving idealistic scenarios. The citizens, however, must take centre stage regarding the smooth functioning and preservation of their art, culture, heritage and all the initiatives taken in that direction.

\section{Attributes of a Smart city with respect to Art, culture and heritage}

The next important question is - Why do we need to give a great amount of importance to art, culture and heritage? $[4,5]$, It is necessary to understand that these three collectively result in the major takeaways for any citizen or visitor in the city. For example, a lot of Chinese cities render excellent souvenirs to people and the fact remains that their porcelain goods are known the world over. Another noteworthy aphorism is that the necessary environment needed to enrich a being in endless ways is provided due to the beauty and richness of the trio.

It doesn't come as a surprise that beautiful things make us happy. We may not be able to identify what beauty really is, but we manage to appreciate it when we see it. It is as though people have a basic common sensibility for beauty. For example, there have been 
experiments where people were to distinguish between real and artificial abstract paintings. Some were original works by Mondrian and Pollock, painted based on strict principles like fractal patterns, whereas the artificial ones were not. A majority of the subjects selected the original works. A similar experiment was conducted on distinguishing originals from abstract artworks that were made either by children or animals. The artworks whose patterns were carefully planned rather than being unstructured were again selected by the participants. Smart cities must be planned carefully for similar results.

Beauty must be considered as one of the most important attributes of a smart city. [6,7], While shaping urban man-made environments and the objects in it, beautification has often been neglected by us in favour of functionality, cost or efficiency. We build concrete jungles where we don't even prefer living. Plain, standardised boxes beside each other. Humans tend to dislike arrangements that do not interest them much. Eye tracking software has shown that people keep focusing on details and ornaments of architecture as compared to swiftly brushing over blank walls. Such dull facades make us miserable. Experiments with skin sensors have shown that seeing them makes us feel bored and uncomfortable. Such boredom, in its turn is associated with increased pulse rates and stress levels. [8], Numerous other experiments have also concluded that aesthetically pleasant surroundings can improve our well-being, cognitive function and mindset. We react mentally and physically to everything in our immediate environment. This is not just visible, but it has been measured too. Beauty is one of those factors that regulates our well being to such an extent that creating objects of utility in a beautiful manner can make them much better! A 2017 study by a hospital employed observing and interviewing the patients as its research methodology to understand factors that help them recover. It was deduced that paintings or art in the areas that they occupied made them feel comfortable and happier about their stay in general. Pleasant surroundings led them to feel better physically! In a similar manner, beautiful music (especially classical music), that is a very integral part of culture, has measurable calming and soothing effects.

Aesthetics also affect us daily. Our happiness, in general, is directly associated with, and depends on aesthetics. Main factors affecting the happiness of adults have been studied (Leyden, Goldberg A., Michelbach, 2011), which reveal a rather unanticipated finding. Apart from factors such as good health and a harmonious family life, individual happiness is affected by how beautiful you find the city you live in. Beauty ranked above cleanliness and safety too! Humans have now become fine tuned to process visual input and assess the surroundings. We are understanding more about how beauty or aesthetics affect us. Beauty satisfies the innate need for meaning in life. It is a sense of feel-good that is an end in itself. It therefore seems like a practical opinion to give more importance to beauty in the new environments that we are creating.

As such, everybody has different ideas and expectations about their smart city. Thus no globally accepted definition can be formulated for it. But as discussed in the introduction, there definitely are certain common elements which contribute in making a smart city. There are major factors like infrastructure, governance, transportation, etc. All these things make a city livable, but they somewhere fail to make a city valuable. The difference here lies in experience and the ways in which a city manifests its rich experiences.

Value is both, an immediate and a long-term notion, one based on sustainable, affirmative experience. Cities, whether old or new, all have a certain story to tell. And, like any brand, it is this immersive experience or storytelling aspect that determines their success. Art, culture and heritage serve as the threads through which the plot of the story is built up and also serve as the characters through which the story unfolds its course. People treasure their rich past, be it their rich kingdoms and dynasties or their long-drawn struggle for freedom. And they also like to preserve and protect everything that reminds them of their heritage. Not only do people treasure their heritage, but they also learn a lot from it. For instance, some very important modern day American buildings like The Lincoln Memorial, The United States Capitol and the Supreme Court Building are actually based on classical Greek architecture and draw inspiration from some of the motifs and stone carving patterns that were used extensively in Mogul architecture are being emulated for various purposes till date. These examples show how much we depend and learn from art, heritage and cultures. The three intertwine from different parts of the world and bring people closer. Together, they make life interesting and break the everyday monotony.

Every city has its own culture and heritage. It reflects in every segment ranging from transport, buildings, shops, public areas, open landscapes to tourist destinations and monuments. Every person residing there represents the city. Public transport vehicles, signage, colours and typefaces play a vital role in visual aesthetics of the city. They are mainly connected with how people or visitors perceive the city, because art and culture have a lot to do with people's mindsets. The visual aspect is very important as it is the first impression of the city. It represents the culture or flavour of the city. The local food, monuments, signage systems communicate directly with the people of the city or those visiting it.

Major smart cities like London, New York have managed to transform their culture into visual communication very effectively. City of London reflects a blend of tradition and modern, whereas a city like New York reflects modern culture. In cities like London and Paris, the facades of many buildings have been maintained in their original state to give the city an even vintage appearance. This goes a long way in helping the city maintain and restore its heritage. On the other hand, New York is known for its sky-scrapers and graffiti culture. The walls of that city have been efficiently treated as the largest canvases that can be painted on. Another notable example is that of a combined effort by a group of artists, Pune Municipal Corporation and Pune Biennale Foundation, who painted India's largest mural at the Yerwada Central Prison in Pune City $[10,11,12]$. 


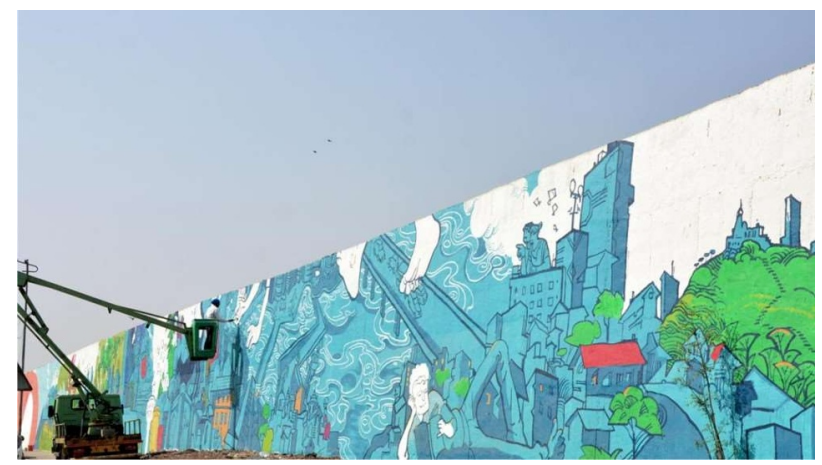

Fig. 1 India's largest mural, Yerawada Jail, Pune.

\section{Art, Culture and Heritage in a Smart City - problem areas - weaknesses, Aesthetics Solutions - signage systems, Tourism solutions, Art narrative}

Visual narration should be consistent everywhere in a smart city, especially at tourist destinations. The city must strive for cleanliness everywhere. For the tourists and visitors, whatever they see is what they get with any new city. In London, all the signage systems are uniform and maintain a systematic visual feel everywhere (Railway Stations, maps, city guides). As far as possible, a universally accepted language and a local language (if any) must be used for important signage, as this makes understanding easy for tourists and citizens alike. Mumbai city, for instance, uses English (considered by most as a universal language) as well as the Devanagari script for most of its important signage.

After understanding the flavour of the city, it is equally important to translate that into the appropriate visual language. For that, a selection of suitable touch points plays a very important role in communication. For any smart city, Airports, Railway Stations, Bus Stops, souvenir shops, restaurants and monuments can be treated as the tier-one touch points. These touch points contribute a lot when it comes to defining the visual language and style of that particular city. The visual communication should convey or reflect the core values of the city in relevant domains like historic, artistic, infrastructural or cultural.

Smart cities in different parts of the world have started including public art installations, pop arts and street displays. These social and personal endeavours leave individuals with an increased sense of pride, belonging and regard for their city, and, in turn, the public benefits from an increased sense of awareness and understanding. The charged atmosphere produced by such endeavours increases the enthusiasm of all. It leads to a feeling of overall well-being and a sense of being connected, which is not possible in a dry, dull environment where people tend to only focus on themselves or their work and are more or less, aloof. To execute such initiatives on city level, good governance, public awareness, right communication, ample opportunities with proper funding and economics are the key factors. If these are not available, then potentially brilliant ideas, very unfortunately, happen to fail due to lack of awareness and correct execution. Therefore, the whole process, from ideation to execution must be fairly well planned with proper government backing. The same applies to the processes of the various other segments of a smart city.

Once the city has developed all the appropriate infrastructure and is sound enough at its own level, then cultural exchange programmes can be undertaken by schools, colleges, universities, special government bodies, NGOs or other bodies that are successfully capable of organising them. They may be national or even international programmes. It is a humble suggestion that these programs can also be added to institutional curriculums at affordable rates. Such vital programmes lead to the participants mutually taking back a plethora of information and memories about each other's culture and a sense of association with the same. This goes a long way in promoting tourism.

\subsection{Given below are some proposed visual design solutions for Pune City on similar lines:}

\subsubsection{City Logo}

Every city has its own identity. Bengaluru city has its own City Logo. It is part English and part Kannada reflecting the true identity of the city. This mixed typography of two languages shows that the Silicon Valley of India is a city that is global as well as local in its culture and lifestyle.

\section{Bencalurs}

Fig. 2 Bengaluru city logo

'Be' and ' $\mathrm{U}$ ' in this logo have been emphasized in red. This is the idea of the logo. The creators of the logo say Bengaluru is a city that allows you to be you. [13]

Similarly, Pune city is known as IT hub as well as Cultural centre. So here is an Ambigram (Flip Script) Logo of Pune created by me.

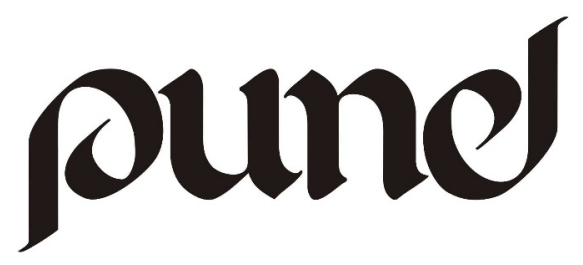

Fig. 3. Pune city ambigram 


\subsubsection{Signage systems}

Signage should carry the same flavour of the city. Here's my design suggestion for Info- signage plaque at Historical monument Shaniwar Wada.

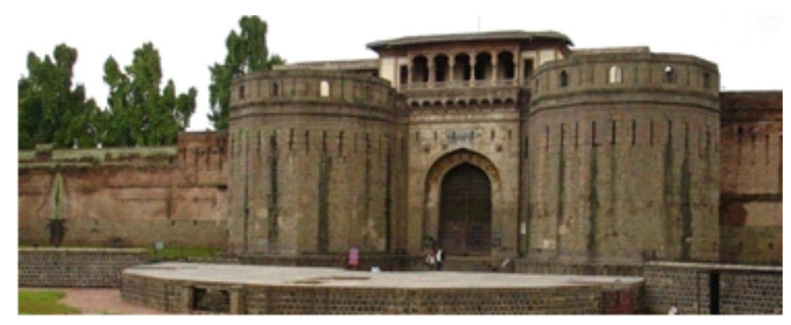

Fig. 4. Shanivar Wada, Pune [14]

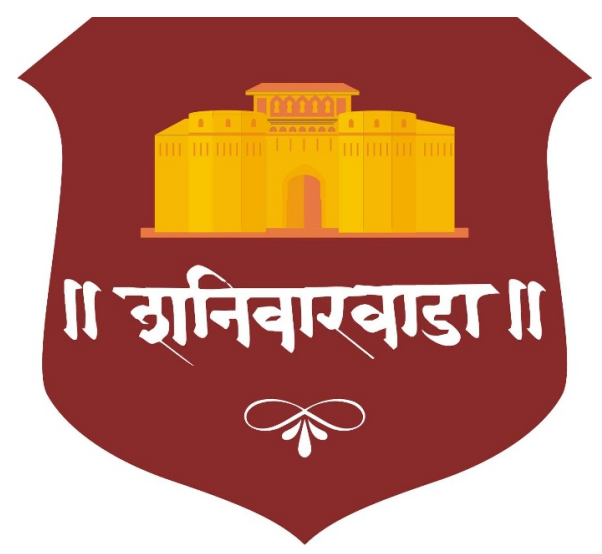

Fig. 5. Calligraphic Devanagari signage design for Shanivar Wada

\subsubsection{Souvenirs}

Souvenirs must be aesthetically pleasing and some may even follow a mood board (that suits the city's culture and the colours that represent it) for collective gifting options.

According to CNN, travellers spend a lot of time and money thinking about souvenirs. Looking at the global economy, over 400 million aggregated hours are spent in gift shops, raking in more than $\$ 2$ billion PER YEAR! In this entire segment, India's contribution is very much negligible. [15]

\subsubsection{City Bus}

City tour buses must look their best and reflect the culture of the city they represent. They must be equipped with all the necessities like a knowledgeable tour guide, brochures, updated city maps, etc. for travel is a major area where tourists could face problems.

\section{Conclusion}

With the making of smart cities, we are witnessing the creation of a completely new era, and not just witnessing it, but creating it as well. In doing so, we must be very cautious about the direction in which we take things. Every little step we take will have a huge impact on the future. For instance, good thought will have to be put into the extent to which we must incorporate techniques like the Internet of Things (IoT) in order not to disrupt the balance between humans and technology or to make humans too dependent on technology. Moving forward in harmony with nature has always been and will always be the key to real growth.

We are fortunate enough to have the perfect chance to responsibly secure a better future for ourselves and for the generations to come. Extremely cautious planning will be required in every sector for the interlinked and overall development of a smart city and that is what will truly make it count.

\section{References}

1. What is smart city, (2017, May 09). Smart Cities Mission. Retrieved from http://smartcities.gov.in/content/innerpage/what -is-smart-city.php

2. G. Hoang, Application of Decision-Making Methods in Smart City Projects: A Systematic Literature Review. Smart Cities, 2, 433 (2019)

3. Art in the Smart City, (n.d.). Retrieved from https://www.mtart.agency/press/read/art-in-thesmart-city/

4. S. Sharma, Smart Cities Unbundled, 35 (2018)

5. What is a smart city. (2015, May 02). Times of India. Retrieved from https://timesofindia.indiatimes.com/what-is-asmart-city-and-how-it-willwork/listshow $/ 47128930 . \mathrm{cms}$ ?from $=\mathrm{mdr}$

6. A. Firodiya, Smart City, 13 (2015)

7. Kurzgesagt, (2018, October 23), Why Beautiful Things Make us Happy, Retrieved from: https://www.youtube.com/watch?v=O5kNPIUV7w

8. Philip C., (2018, July 04) Five Beautiful American Buildings Based on Classical Greek Architecture. Retrieved from https://usa.greekreporter.com/2018/07/04/fivebeautiful-american-buildings-based-onclassical-greek-architecture/

9. L. Suzuki, (2018, November 29) Machine learning and $\mathrm{AI}$ - ensuring fairness in smart cities. Smart City Research - UCL - UK. Retrieved from http://www.smartcityresearch.com/

10. Mihir B, (2017, February 26) India's largest mural unfolds at Yerawada Jail. Times of India. Retrieved from: https://timesofindia.indiatimes.com/entertainme nt/marathi/movies/news/indias-largest-mural-inpune/articleshow/57160142.cms

11. Payal M, (2017, November 15) India's Largest Mural Livens Up The Walls Of Maharashtra's Largest Jail. Retrieved from: https://homegrown.co.in/article/801972/indiaslargest-mural-livens-up-the-walls-ofmaharashtras-largest-jail 
12. Yerwada Mural (n.d.) JPEG, Pune Biennale. Retrieved

from

https:/www.punebiennale.in/images/ourwork/yerwada-mural/Song-of-the-City-1.jpg

13. Madur, (2018, January 02), Bengaluru Logo Bangalore Gets Its Own Brand Identity. Retrieved from: https://www.karnataka.com/bangalore/bengalur u-logo/

14. Shaniwarwada, (2019), JPEG, Accessed on 20 November 2019, Retrieved from: https://in.bmscdn.com/nmcms/events/banner/de sktop/media-desktop-shaniwarwada-2019-1-12t-2-36-26.jpg

15. Alan B, (n.d.) The Grand Significance Of Cheap Souvenirs. Let's Roam. Retrieved from: https://www.letsroam.com/explorer/the-grandsignificance-of-cheap-souvenirs/ 